\title{
A EDUCAÇÃO FÍSICA NO PROCESSO INCLUSIVO: \\ UM ESTUDO DE CASO NO MUNICÍPIO DE SÃO JOÃO DA \\ BOA VISTA-SP ${ }^{1}$
}

Dnda. Rachel Barbosa Poltronieri Florence

Dr. Paulo Ferreira de Araújo

Faculdade de Educação Física/UNICAMP

\section{Resumo}

Considerar a diversidade presente entre os alunos nas instituições escolares da rede municipal e estadual de ensino do município de São João da Boa Vista-SP requer procedimentos que nos remetam à flexibilidade e dinamismo nos currículos, compromisso e responsabilidade dos professores, cooperação dos pais e apoio da comunidade de forma a atender efetivamente aos alunos com necessidades educacionais especiais. Mediante o atual processo inclusivo, como forma a colaborar para um melhor entendimento sobre o assunto, como recurso metodológico para este estudo, para contemplar a prática da educação física face à inclusão nas escolas, foi realizada uma pesquisa qualitativa do tipo estudo de caso, com a realização de entrevistas semiestruturadas com os professores de educação física que atuam junto a estes alunos especiais na rede regular. Como amostra para a coleta de dados, delimitou-se o Ciclo I da etapa do ensino fundamental de escolas do município que incorporaram a inclusão em seu atendimento de alunos com necessidades educacionais especiais.

Palavras-Chave: Educação Especial; Educação Física; Diversidade.

\section{Introdução}

Refletir sobre o portador de necessidades especiais e sua relação com a educação física nos leva a compreensão de como é preciso atender e entender suas necessidades respeitando as características peculiares sem ocultar seu potencial, contextualizando-o num princípio fundamental para as relações humanas: a diversidade. A diversidade tem sido a palavra chave para o desencadeamento do atual processo inclusivo estabelecendo aos portadores de necessidades especiais o atendimento educacional, preferencialmente na rede regular de ensino. O papel do professor de educação física neste momento, não difere do que já vem ocorrendo: o de proporcionar vivências e oportunidades motoras adaptando-se às mais diferentes realidades.

\footnotetext{
1 Este artigo é parte de minha dissertação de Mestrado intitulada "A Educação Física na Rede Pública do Município de São João da Boa Vista-SP e o Portador de Necessidades Especiais: do direito ao alcance”, sob a orientação do Professor Dr. Paulo Ferreira de Araújo/FEF/ DEAFA/UNICAMP.
} 
Neste sentido destacamos com Ferreira (1998, p. 22) a análise de que,

a área de educação especial vive um importante momento de inflexão, num contexto de amplas reformas na educação geral, e que colocam novas questões para o desafio de assegurar uma educação de qualidade para os alunos com necessidades especiais.

Esta educação especial deve se espelhar em um conjunto de recursos educacionais e de estratégias de apoio que estejam à disposição de todos os alunos, oferecendo diferentes alternativas de atendimento.

Concordamos com Santos (2001, p. 119), que sustenta a concepção de que para a inclusão de todos os alunos, é preciso que todos os educadores se proponham a novas reformulações, novos posicionamentos, que haja a modernização da escola, modificação das práticas educativas para que de fato todos os alunos realmente aprendam.

Stainback e Stainback (1999) acreditam que a filosofia contida nas salas de aula inclusivas estabelece que é importante que as crianças aprendam e que, desta forma, sejam parte do sistema escolar e de sua comunidade. Neste sentido, destaca-se a diversidade enquanto peça fundamental para este processo, pois se acredita na mesma enquanto fator que otimize a socialização da turma e propicie maiores oportunidades de aprendizagem. A escola inclusiva é definida como aquela em que todos os alunos são educados nas classes regulares, todos são aceitos, todos colaboram e se ajudam mutuamente de forma a suprir as necessidades educacionais, decorrentes das atividades que também são desafiadoras.

Através das reflexões dos autores citados, observamos que a educação especial passou a ser vista e destinada aos alunos com necessidades especiais, mas para que o sucesso possa ser alcançado, é necessário atender às chamadas necessidades básicas de aprendizagem de cada aluno, adotando - se práticas pedagógicas, ampliando-se os conhecimentos, destrezas e valores imperiosos para a sobrevivência, bem como favorecendo ao exercício da cidadania de forma a desenvolver as próprias capacidades, de tomar decisões fundamentadas e continuar o processo de aprendizagem de forma permanente (TORRES, 2001). 


\section{Metodologia}

Para que pudéssemos relacionar a educação física frente a este novo paradigma da inclusão, realizou-se uma pesquisa qualitativa, do tipo estudo de caso no município de São João da Boa Vista, estado de São Paulo, com a rede regular pública estadual e municipal de ensino, utilizando como técnica para a coleta de dados a entrevista semiestruturada.

O universo da pesquisa foi delimitado através das escolas estaduais e municipais do município que atendem ao ensino fundamental (Ciclo I - de $1^{\mathrm{a}}$ à $4^{\mathrm{a}}$ séries e Ciclo II de $5^{\mathrm{a}}$ à $8^{\mathrm{a}}$ séries) e que recebem alunos portadores de necessidades educacionais especiais. Assim, para o estabelecimento da coleta de dados realizado nas escolas, enviamos inicialmente um ofício à Diretoria Regional de Ensino de São João da Boa Vista, solicitando o nome de todas as escolas e o número de alunos das mesmas da rede estadual deste município, nomeando, entre elas, as que tinham alunos com necessidades educacionais especiais. Como resposta, obtivemos que, das treze escolas vinculadas a este departamento, três recebiam alunos com necessidades especiais educacionais do ensino fundamental. Em relação às escolas da rede municipal, foram realizados os seguintes passos para a delimitação do nosso estudo: levantamento de dados junto à psicóloga responsável pelo setor, sobre o número de escolas do município em relação ao ensino fundamental; como resposta obtivemos o número de oito escolas que atendem ao Ciclo I do ensino fundamental, isto é de $1^{\text {a }}$ à $4^{\text {a }}$ séries; levantamento por telefone junto às coordenações das referidas escolas para a obtermos a informação sobre a presença ou não de alunos com necessidades educacionais especiais; das oito escolas, três recebem alunos com necessidades educacionais especiais.

O universo da pesquisa reduziu-se a seis escolas (três estaduais e três municipais), representando o todo referente à cidade e as informações obtidas caracterizaram o processo de inclusão da educação física nas escolas da rede pública. Para tanto, será apresentado, a seguir, com o propósito de atender aos objetivos deste estudo, a descrição e apresentação dos dados coletados nas entrevistas com três das doze escolas municipais, e três das treze escolas estaduais, que compõem o quadro educativo do município. Para uma melhor organização, dividimos os dados das escolas municipais e estaduais em três blocos: identificação, desenvolvimento e atitudes. Em 
relação às escolas adotamos o critério de escolas $a$ para as municipais e $b$ referindo-se às escolas estaduais. O número total de entrevistados foram dez, sendo que três eram alunos estagiários do curso de educação física da Faculdade do Município, seis eram regentes de sala e somente um era professor de Educação Física.

O Quadro 1 conforme demonstrado a seguir, nos forneceu a identificação inicial para que pudéssemos delimitar a amostra que caracterizasse a presente pesquisa como estudo de caso. Dentre o universo escolar municipal, encontramos um total de doze escolas. Dentre estas, duas recebem somente alunos do Ciclo I ( $1^{\mathrm{a}}$ à $4^{\mathrm{a}}$ séries $)$ do ensino fundamental; seis são destinados ao Ciclo I e Educação Infantil. As quatro escolas restantes são direcionadas exclusivamente para a educação infantil.Portanto, foi necessário identificarmos o número total das escolas municipais e, dentre estas, a verificação das que recebiam portadores de necessidades educacionais especiais.

Através do Quadro 2, podemos observar que a escola $1 b$, possui três portadores de necessidades educacionais especiais na rede regular: um deficiente mental e um deficiente físico que se encontram na $1^{\text {a }}$ série e um deficiente visual na $4^{\text {a }}$ série $^{2}$. A escola $2 b$ recebe dois portadores de deficiência mental na $2^{\mathrm{a}}$ série da classe regular e a escola $3 a$, possui um aluno portador de deficiência mental na $1^{\mathrm{a}}$ série, outro na $2^{\mathrm{a}}$ e $3^{\mathrm{a}}$ séries, e três na $4^{\mathrm{a}}$ série.

Em relação à participação destes alunos nas aulas de educação física, pudemos verificar que estes gostam e participam. A parcialidade apresentada no quadro em relação ao envolvimento deles resulta da falta de motivação que alguns sentem ao não conseguirem realizar a atividade que foi proposta.

${ }^{2}$ Gostaríamos de esclarecer que a denominação DA (deficiente auditivo), DV (deficiente visual), DM (deficiente mental, DF (deficiente físico) se justifica por ser desta forma que as escolas se organizam nas suas classificações. 
QUADRO 1 - IDENTIFICAÇÃO

\begin{tabular}{|c|c|c|c|c|c|c|c|c|c|c|c|c|c|}
\hline Escolas Municipais & & $1 a$ & $2 a$ & $3 a$ & $4 a$ & $5 a$ & $6 a$ & $7 a$ & $8 a$ & $9 a$ & $10 a$ & $11 a$ & $\begin{array}{r}12 \\
a\end{array}$ \\
\hline \multirow{3}{*}{$\begin{array}{l}\text { Recebem alunos com } \\
\text { necessidades } \\
\text { especiais }\end{array}$} & Sim & \multirow{4}{*}{460} & \multirow[t]{2}{*}{$\mathrm{X}$} & \multirow[t]{2}{*}{$\mathrm{X}$} & & & & & & & & & \\
\hline & Não & & & & $\mathrm{X}$ & $\mathrm{X}$ & $\mathrm{X}$ & $\mathrm{X}$ & $\mathrm{x}$ & $\mathrm{X}$ & $\mathrm{x}$ & $\mathrm{X}$ & $\mathrm{X}$ \\
\hline & $\begin{array}{c}\text { Total } \\
\text { do no. } \\
\text { de } \\
\text { alunos } \\
\end{array}$ & & 260 & 86 & 490 & 117 & 87 & 79 & 127 & & & & \\
\hline \multirow{3}{*}{$\begin{array}{c}\text { Professor } \\
\text { responsável pelas } \\
\text { aulas de Educação } \\
\text { Física }\end{array}$} & $\begin{array}{l}\text { Regent } \\
\text { e }\end{array}$ & & & 4 & & & & & & & & & \\
\hline & $\begin{array}{c}\text { Estagi } \\
\text { ário de } \\
\text { Ed. } \\
\text { Física } \\
\end{array}$ & \multirow[t]{3}{*}{1} & 1 & & & & & & & & & & \\
\hline & $\begin{array}{l}\text { Profes } \\
\text { sor de } \\
\text { Ed. } \\
\text { Física } \\
\end{array}$ & & & & & & & & & & & & \\
\hline \multirow{2}{*}{$\begin{array}{l}\text { Freqüûncia das aulas } \\
\text { de Ed. Física }\end{array}$} & $\begin{array}{c}1 \text { vez } \\
\text { por } \\
\text { seman } \\
\text { a }\end{array}$ & & & & & & & & & & & & \\
\hline & \begin{tabular}{|c|}
2 vezes \\
por \\
seman \\
a \\
\end{tabular} & $\mathrm{x}$ & $\mathrm{x}$ & $\mathrm{X}$ & & & & & & & & & \\
\hline \multirow[b]{2}{*}{ Ensino Fundamental } & Ciclo I & \multirow[t]{3}{*}{$\mathrm{x}$} & $\mathrm{X}$ & $\mathrm{X}$ & & & & & & & & & \\
\hline & $\begin{array}{c}\text { Ciclo } \\
\text { II }\end{array}$ & & & & & & & & & & & & \\
\hline Educação Infantil & & & & & & & & & $\mathrm{X}$ & $\mathrm{X}$ & $\mathrm{x}$ & $\mathrm{X}$ & \\
\hline
\end{tabular}

QUADRO 2 - DESENVOLVIMENTO

\begin{tabular}{|c|c|c|c|c|c|c|c|c|c|c|}
\hline \multirow{2}{*}{$\begin{array}{l}\text { Escola } \\
\text { s } \\
\text { Munic } \\
\text { ipais }\end{array}$} & \multirow{2}{*}{ Série } & \multicolumn{4}{|c|}{ Tipos de deficiência } & \multicolumn{3}{|c|}{ Participação } & \multicolumn{2}{|c|}{ Envolvimento } \\
\hline & & DM & DA & DV & DF & Sim & Não & Às vezes & Total & Parcial \\
\hline \multirow{4}{*}{$\begin{array}{l}\text { Escola } \\
\qquad 1 b\end{array}$} & $1^{a}$ & 1 & & & 1 & $\mathrm{X}$ & & & $\mathrm{X}$ & \\
\hline & $2^{\mathrm{a}}$ & & & & & & & & & \\
\hline & $4^{\mathrm{a}}$ & & & 1 & & $\mathrm{X}$ & & & & X \\
\hline & $1^{\mathrm{a}}$ & & & & & & & & & \\
\hline \multirow{3}{*}{$\begin{array}{l}\text { Escola } \\
2 b\end{array}$} & $2^{\mathrm{a}}$ & 2 & & & & X & & & & $\mathrm{x}$ \\
\hline & $\begin{array}{l}3^{\mathrm{a}} \\
4^{\mathrm{a}}\end{array}$ & & & & & & & & & \\
\hline & $1^{\mathrm{a}}$ & 1 & & & & & & $\mathrm{X}$ & & $\mathrm{X}$ \\
\hline \multirow{3}{*}{$\begin{array}{c}\text { Escola } \\
\mathbf{3 b}\end{array}$} & $2^{\mathrm{a}}$ & 1 & & & & $X$ & & & & $\mathrm{X}$ \\
\hline & $3^{\mathrm{a}}$ & 1 & & & & $X$ & & & $X$ & \\
\hline & $4^{\mathrm{a}}$ & 3 & & & & $\mathrm{X}$ & & & $X$ & \\
\hline
\end{tabular}


QUADRO 3 - ATITUDES

\begin{tabular}{|c|c|c|c|c|c|c|c|c|c|}
\hline \multirow{3}{*}{$\begin{array}{c}\text { Escolas } \\
\text { Municipais }\end{array}$} & \multirow{3}{*}{$\begin{array}{l}\text { Professoras } \\
\text { Entrevistadas }\end{array}$} & \multirow{2}{*}{\multicolumn{2}{|c|}{ Orientações da Escola }} & \multicolumn{6}{|c|}{ Modificações após o recebimento de alunos especiais } \\
\hline & & & & \multicolumn{3}{|c|}{ Ações } & \multicolumn{3}{|c|}{ Estruturas } \\
\hline & & Sim & Não & Sim & Não & Parcial & $\begin{array}{l}\mathbf{S i} \\
\mathrm{m}\end{array}$ & Não & Parcial \\
\hline $1 \mathrm{~b}$ & 1 & $\mathrm{X}$ & & $\mathrm{X}$ & & & $\mathrm{X}$ & & \\
\hline \multirow{2}{*}{$2 b$} & 1 & $\mathrm{X}$ & & $\mathrm{X}$ & & & & $\mathrm{X}$ & \\
\hline & 1 & & $\mathrm{X}$ & $\mathrm{X}$ & & & & $\mathrm{X}$ & \\
\hline \multirow{3}{*}{$3 b$} & 2 & & $\mathbf{X}$ & & $\mathbf{x}$ & & & $\mathbf{x}$ & \\
\hline & 3 & $\mathbf{X}$ & & $\mathbf{X}$ & & & & $\mathbf{X}$ & \\
\hline & 4 & $\mathbf{x}$ & & $\mathbf{x}$ & & & & $\mathbf{x}$ & \\
\hline
\end{tabular}

Em relação ao Quadro 3, observou-se através dos relatos das entrevistas que nas escolas $1 b$ e $2 b$, houve orientações no sentido de esclarecimento à professora sobre peculiaridades dos alunos especiais, mas na escola $3 b$, notamos que para as quatro professoras entrevistadas as orientações preliminares foram insuficientes e algumas vezes inexistentes. Houve o empenho das professoras para o desenvolvimento das atividades de forma a atingir a todos os alunos.

De forma geral, a escola se mobilizou após receber os alunos portadores de necessidades educacionais especiais, procuraram caminhos para a eficiência no oferecimento das atividades. Outro ponto a ser destacado foi o recebimento de fichas médicas referentes aos alunos para as professoras como forma de orientação.

O quadro 4 apresentado a seguir, representa a totalidade do universo escolar estadual do município. O número de escolas é treze, das quais três recebem portadores de necessidades educacionais especiais. Das treze escolas, doze possui o ensino fundamental, entre elas cinco apenas com o Ciclo I, duas com Ciclo I e parte do Ciclo II, duas com o Ciclo II, duas com o Ciclo II e ensino Médio e uma somente com o ensino médio. Dentre as escolas inclusivas, encontramos, na escola $1 b$, as professoras regentes de classe como responsáveis pelas atividades de Educação Física. Na escola $2 b$, as aulas ficam a critério de uma estagiária da Faculdade de Educação Física do município. Na escola $3 b$, ministra as aulas de Educação Física um professor especialista.Com relação à freqüência das atividades, somente uma classe da escola $1 b$, ministra suas aulas uma vez por semana, as demais estabelecem duas vezes por semana. 
QUADRO 4 - IDENTIFICAÇÃO

\begin{tabular}{|c|c|c|c|c|c|c|c|c|c|c|c|}
\hline \multirow[b]{2}{*}{$\begin{array}{l}\text { Escolas } \\
\text { Estaduais }\end{array}$} & \multicolumn{3}{|c|}{$\begin{array}{c}\text { Recebem alunos } \\
\text { com necessidades } \\
\text { especiais }\end{array}$} & \multicolumn{3}{|c|}{$\begin{array}{c}\text { Professor responsável pelas } \\
\text { aulas } \\
\text { de Educação Física } \\
\end{array}$} & \multicolumn{2}{|c|}{$\begin{array}{l}\text { Freqüência das } \\
\text { aulas de Ed. } \\
\text { Física }\end{array}$} & \multicolumn{2}{|c|}{$\begin{array}{c}\text { Ensino } \\
\text { Fundamental }\end{array}$} & \multirow[b]{2}{*}{$\begin{array}{l}\text { Ensino } \\
\text { Médio }\end{array}$} \\
\hline & Sim & Não & $\begin{array}{c}\text { Total } \\
\text { de } \\
\mathbf{n}^{\circ} \text { de } \\
\text { alunos } \\
\end{array}$ & Regente & $\begin{array}{c}\text { Estagiário } \\
\text { de } \\
\text { Ed. } \\
\text { Física } \\
\end{array}$ & $\begin{array}{l}\text { Professor } \\
\text { de Ed. } \\
\text { Física }\end{array}$ & $\begin{array}{l}1 \text { vez } \\
\text { por } \\
\text { semana }\end{array}$ & $\begin{array}{c}2 \text { vezes } \\
\text { por } \\
\text { semana }\end{array}$ & $\begin{array}{c}\text { Ciclo } \\
\text { I }\end{array}$ & $\begin{array}{c}\text { Ciclo } \\
\text { II }\end{array}$ & \\
\hline $1 \mathrm{~b}$ & $\mathbf{X}$ & & 706 & 2 & & & $\mathbf{X}$ & $\mathbf{X}$ & $\mathbf{X}$ & & \\
\hline $2 \mathrm{~b}$ & $\mathbf{X}$ & & 975 & & 1 & & & $\mathbf{X}$ & $\mathbf{X}$ & $\mathbf{X}$ & \\
\hline $3 \mathbf{b}$ & $X$ & & 595 & & & 1 & & $\mathbf{X}$ & $\mathbf{X}$ & & \\
\hline $4 \mathrm{~b}$ & & $\mathbf{X}$ & 400 & & & & & & $\mathbf{X}$ & & \\
\hline $5 \mathrm{~b}$ & & $\mathbf{X}$ & 718 & & & & & & $\mathbf{X}$ & $\mathbf{X}$ & \\
\hline $6 \mathrm{~b}$ & & $\mathbf{X}$ & 1.481 & & & & & & & & $\mathbf{X}$ \\
\hline $7 \mathrm{~b}$ & & $\mathbf{X}$ & 1.003 & & & & & & & $\mathbf{X}$ & \\
\hline $8 \mathrm{~b}$ & & $\mathbf{X}$ & 1.318 & & & & & & & $\mathbf{X}$ & $\mathbf{X}$ \\
\hline 9 b & & $\mathbf{X}$ & 1.162 & & & & & & & $X$ & \\
\hline $10 \mathrm{~b}$ & & $\mathbf{X}$ & 126 & & & & & & $\mathbf{X}$ & & \\
\hline $11 \mathrm{~b}$ & & $\mathbf{X}$ & 1.376 & & & & & & & $\mathbf{X}$ & $\mathbf{X}$ \\
\hline $12 \mathrm{~b}$ & & $\mathbf{X}$ & 596 & & & & & & X & & \\
\hline $13 \mathrm{~b}$ & & $\mathbf{X}$ & 222 & & & & & & $\mathbf{X}$ & & \\
\hline
\end{tabular}


QUADRO 5 - DESENVOLVIMENTO

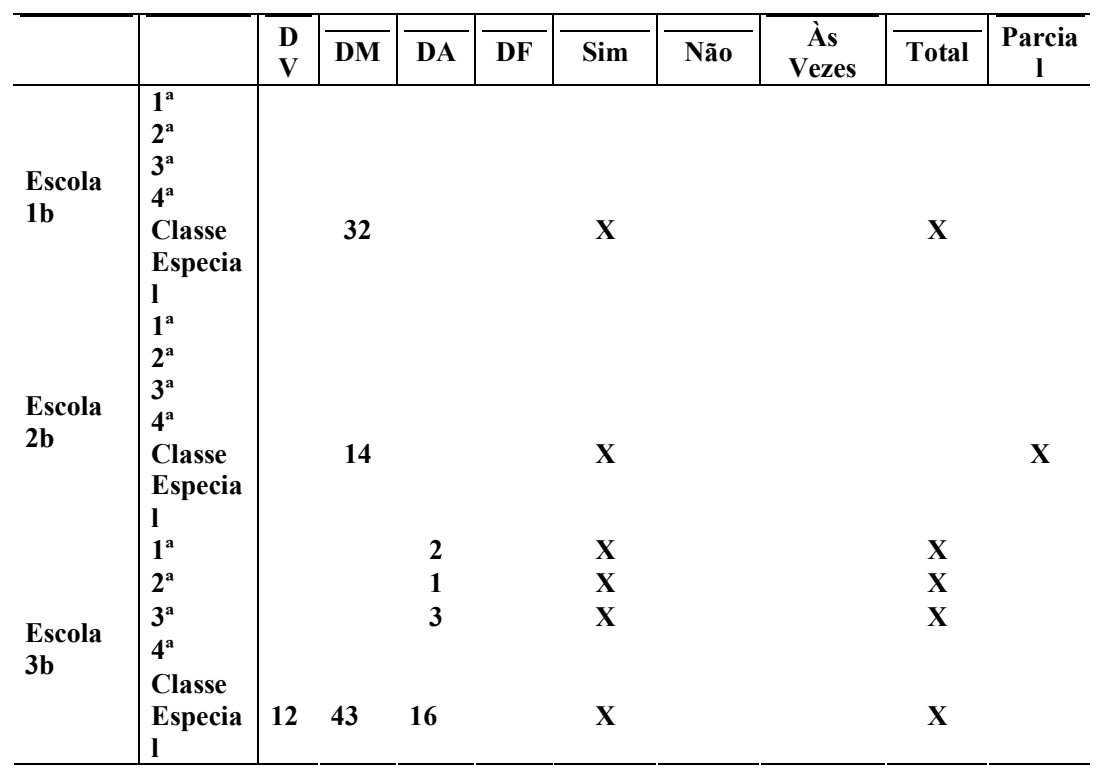

Em relação ao Quadro 5, verificamos que a escola $1 b$ ainda permanece com duas classes especiais como forma de atendimento aos alunos portadores de necessidades educacionais especiais. Ambas são compostas pelos denominados deficientes mentais. É importante ressaltarmos que, em ambas as classes, também são considerados os alunos com dificuldades de aprendizagem, conforme relatado nas entrevistas.

Ainda sobre a escola $1 b$, observamos que, nas duas entrevistas realizadas, existe a participação de todos os alunos nas aulas de educação física. As entrevistadas esclarecem, de forma implícita, que procuram desenvolver atividades que despertem o interesse dos alunos. 
Na escola $2 b$, encontramos uma classe especial também composta de deficientes mentais. Também podemos verificar, no relato da professora, que a participação dos mesmos varia conforme a realização ou não das atividades propostas.

Com relação à escola $3 b$, constatamos a presença de classes especiais: duas de deficientes mentais, uma de deficientes visuais, uma de deficiente auditivo e, nas classes regulares, encontramos um deficiente auditivo na $2^{\mathrm{a}}$ série, três deficientes auditivos na $3^{\mathrm{a}}$ série e dois deficientes auditivos na $1^{\mathrm{a}}$ série. Ou seja, a escola possui atendimento tanto em classes especiais quanto em classes regulares.

A participação dos alunos nas aulas de Educação Física é considerada total, com êxito, mesmo porque existe interesse, vontade e empenho do professor no planejamento das atividades para que as mesmas tenham êxito, observados através dos relatos.

QUADRO 6 - ATITUDES

\begin{tabular}{|c|c|c|c|c|c|c|c|c|c|}
\hline \multirow{3}{*}{$\begin{array}{c}\text { Escolas } \\
\text { Estaduai } \\
\quad s\end{array}$} & \multirow{3}{*}{$\begin{array}{c}\text { Professoras } \\
\text { Entrevistada } \\
\text { s }\end{array}$} & \multirow{2}{*}{\multicolumn{2}{|c|}{$\begin{array}{l}\text { Orientações } \\
\text { da Escola }\end{array}$}} & \multicolumn{6}{|c|}{$\begin{array}{l}\text { Modificações após o Recebimento de } \\
\text { Alunos Especiais }\end{array}$} \\
\hline & & & & \multicolumn{3}{|c|}{ Ações } & \multicolumn{3}{|c|}{ Estruturas } \\
\hline & & Sim & Não & Sim & Não & $\begin{array}{c}\text { Parcia } \\
1\end{array}$ & Sim & Não & $\begin{array}{c}\text { Parcia } \\
1 \\
\end{array}$ \\
\hline \multirow{2}{*}{ 1b } & 1 & $\mathrm{X}$ & & $\mathrm{X}$ & & & & & $\mathrm{X}$ \\
\hline & 2 & $\mathrm{X}$ & & $\mathrm{X}$ & & & & & $\mathrm{X}$ \\
\hline $2 \mathbf{b}$ & 1 & & $\mathrm{X}$ & & $X$ & & & $X$ & \\
\hline $\mathbf{3 b}$ & 1 & $\mathrm{X}$ & & $\mathrm{X}$ & & & & & $X$ \\
\hline
\end{tabular}

A escola $1 b$, do Quadro 6 possui duas professoras que foram entrevistadas. A professora 1 nos relatou que recebeu orientações tempos atrás sobre atividades físicas que poderiam ser desenvolvidas, assim como nas htp - horário de trabalho pedagógico e também da Diretoria Regional de Ensino de São João da Boa Vista. Portanto em termos de ações, as informações estão chegando a esta professora. Em termos de estruturas, permanece como está. A professora 2 também recebeu as mesmas orientações acima citadas e acrescentou um ponto fundamental para nosso entendimento: a troca de experiências com professores de outras escolas. Sem dúvida, é um trabalho muito rico. A referida professora também considera que a escola está preparada para receber estes alunos e que procura desempenhar seu papel de recebê-los de forma a participarem de todos os projetos desenvolvidos pela escola. 
As ações são contínuas através de reuniões pedagógicas por meio de informações e orientações, de forma a se sentirem confiantes. Com relação às estruturas, pouco se modificou, em razão de ser uma escola antiga e com suas instalações consideradas limitadas.

$\mathrm{Na}$ escola $2 b$, a professora alega não ter recebido informações prévias, mas houve iniciativa desta em promover o desenvolvimento das aulas de Educação Física. As ações e estruturas foram consideradas através das salas de recursos (computadores, som, televisão e vídeo).

O professor de Educação Física da escola $3 b$ considerou que não recebeu informações anteriores da escola, mas na verdade, em nossas análises, consideramos como uma excelente indicação para qualquer professor: a de ministrar suas aulas para os alunos portadores de necessidades especiais da mesma forma que a faz com os outros. O professor alega que existe um sólido trabalho em termos de ações sobre essa temática. Apenas faltam algumas modificações em termos de estruturas físicas, pois há um deficiente físico e não há rampas pela escola. Ele confirma que, se os alunos vão para a escola, deve existir uma estrutura que sustente este sistema.

\section{Considerações Finais}

A Educação Física, como componente curricular obrigatório da escola, deve fazer parte do projeto pedagógico da mesma. Atualmente, seu campo de inserção nas escolas divide-se em professores regentes de classe que são considerados como habilitados a ministrarem as aulas de educação física para os alunos da educação infantil e Ciclo I e professores especialistas atuando obrigatoriamente no Ciclo II.

Portanto, podemos considerar alguns pontos relevantes em relação aos dados coletados da pesquisa. De forma geral, observamos que o processo de inclusão no município de São João da Boa Vista/SP está acontecendo, de forma tímida; não pudemos verificar esse processo de forma absoluta. Contudo, é preciso ressaltar que, em relação à educação física, o processo caminha de forma positiva, visto que na maioria das escolas há a participação e envolvimento dos alunos nas atividades. São momentos prazerosos. A insegurança que alguns professores da rede regular sentem por se considerarem não aptos para trabalhar com alunos especiais, cai por terra ao 
vivenciarem a rica experiência em ensinar todos os alunos de sua classe, com suas peculiaridades. Com a participação e o envolvimento dos alunos nas atividades, mesmo que às vezes de forma parcial, os professores se certificam de que os problemas não são tantos como se pensava e que as suas práticas e experiências dão conta das situações de aprendizagem. As necessidades de adaptações são sinalizadas pelo próprio aluno, desta forma, o professor vai se conscientizando de que os alunos seguem caminhos diferentes na realização das atividades e isto é normal.

Concordamos com Rodrigues (1991) que analisa o quanto é importante para o desenvolvimento do portador de necessidades educacionais especiais a atuação de outros profissionais. Num trabalho em equipe, as estratégias se completam. Não conseguiremos abrir as escolas às diferenças e à qualidade de ensino, onde todos devem ser bem-vindos se não estivermos dispostos a repensar nossos valores e costumes, procurando por uma sociedade mais justa e igualitária. Todos nós somos responsáveis pelo compromisso de transformar a escola e adequá-la ao terceiro milênio.

\section{Abstract}

To consider the actual diversity among the pupils in school institutions of the municipal and state education in São João da Boa Vista city, it requires a conduct in order to take us to flexibility and dynamism in the curriculum, responsibility of the professor, cooperation of the parents and support to the community for taking care of the pupils special necessities education. By means of the current inclusive process, just to collaborate for a better agreement on the subject, as methodology resource for this study, to contemplate practical of the physical education in face to the inclusion in the schools, a qualitative research of the type case was carried through study, with the accomplishment of interviews half-structuralized with the professors of physical education who act together to those special pupils in the regular net. As a sample for the collection data, Cycle I of the basic education schools of the city was delimited and they incorporated the inclusion in its attendance of pupils with educational special necessities.

Key-Words: Physical Education; Special education; Diversity.

\section{Referências Bibliográficas}

FERREIRA, J. R. Ética, cidadania, escola e instituições para pessoas com deficiência.

In: CONGRESSO IBERO-AMERICANO DE EDUCAÇÃO ESPECIAL, 3., Foz do

Iguaçu, 1998. Anais... Foz do Iguaçu, 1998. v. 1. 
RODRIGUES, J. L. A Educação Física no contexto interdisciplinar e a pessoa portadora de deficiência. 1991. 109f. Dissertação (Mestrado em Educação Física) Faculdade de Educação Física, Universidade Estadual de Campinas, Campinas, 1991.

SANTOS, M. S. dos. O desafio de uma experiência. In: MANTOAN, M. T. E. Caminhos pedagógicos da inclusão: como estamos implementando a educação (de qualidade) para todos nas escolas brasileiras. São Paulo: Memnon, 2001.

TORRES, R. M. Educação para todos: a tarefa por fazer. Porto Alegre: Artmed, 2001. STAINBACK, S.; STAINBACK, W. Inclusão: um guia para educadores. Porto Alegre: Artmed, 1999. 